\title{
Tidal Dynamics along the Eastern Coast of the Red Sea
}

\author{
V. R. Shamji \\ Faculty of Maritime, Studies, King Abdulaziz University, Jeddah, Kingdom of Saudi Arabia \\ Email: vrshamji@gmail.com
}

How to cite this paper: Shamji, V.R. (2019) Tidal Dynamics along the Eastern Coast of the Red Sea. Open Access Library Journal, 6: e5341.

https://doi.org/10.4236/oalib.1105341

Received: March 15, 2019

Accepted: April 7, 2019

Published: April 10, 2019

Copyright $\odot 2019$ by author(s) and Open Access Library Inc.

This work is licensed under the Creative Commons Attribution International License (CC BY 4.0).

http://creativecommons.org/licenses/by/4.0/

\section{(c) () Open Access}

\begin{abstract}
Understanding of tidal components is of paramount importance in assessing the influence of tides on coastal processes. The present study focuses on comprehensive tidal analysis in the eastern coast of the Red Sea, Saudi Arabia. The analysis carried out spatial and temporal scale to unravel the tidal dynamics along the coastal regions of the eastern coast of the Red Sea. Time series data from the seven coastal stations along the western coast of the Saudi Arabia were used for tidal analysis. T_TIDE analyses were performed for extracting the tidal constituents. The study reveals the variations of tidal constituent temporal and spatial basis. The analysis well predicted water levels and verified it with field data.
\end{abstract}

\section{Subject Areas}

Environmental Sciences

\section{Keywords}

Tidal Dynamics, Coastal Processes, Form Factor

\section{Introduction}

The Red Sea is connected to the Indian Ocean; no direct tidal waves enter from Indian Ocean to Red sea and hence the tidal range is less in the Red sea [1]. The Red Sea has more practical importance in connecting Arabian Sea and Mediterranean Sea. The tidal dynamics in the Red Sea have more importance, especially coral protected coastal areas. Even though the tidal range is small, the influence of the tide has a major role in the coral life and coastal protection. Hence, a comprehensive study on the dynamics of tides is lacking in this region. Since the area belongs to the micro tidal region the influence of tide and its associated currents are more prominent in the coastal areas, than the open ocean, where 
anthropogenic activities are more. Since the eastern coast of the Red Sea is protected by coral reef, the coastal physical processes play a major role in the in the life span of coral reef [2].

Hence, a numerical modeling study was carried out to unravel the dynamics of tides in the eastern coast of the Red Sea, where such site-specific studies are few. The tidal analysis was carried out about the eastern coast of the Red Sea. The main objective of the study is to analysis the tidal dynamics along the eastern coast of the Red Sea using T-Tide tool and its related practical applications in this region. The study also focuses to bring out spatial variation of tidal constituents along the eastern part of the Red Sea and its practical importance. The present investigations have more importance that can be used in the field of academic research and developments. The present investigation was carried out with comprehensive field data collected from even distributed tide gauges data along the eastern coast of the Red Sea and hence the scope of the study is more. The study area, Red Sea is about $2250 \mathrm{~km}$ long and, at its widest point, $355 \mathrm{~km}$ wide [3] [4] [5]. The topography of the Red Sea is from north to south starting from the Gulf of Aqaba, with coastline with low cliffs and sandy beaches [6]. There are fringing reefs and reef-edged sharms (e.g. Sharm Obhur) are located along the coastline. Since the average tidal range is less in the Red Sea coast, the inter-tidal zones are narrow. The Farsan Islands consist of many reefs and emerged reef islands showing tectonic dislocation [7]. The present investigation carried out spatially along these environmentally varying coastal areas with time series data. The study also reveals the annual variations of observed water levels using location-specific tide gauge observations.

Red sea is characterised with different weather pattern; monsoon system affects the wind pattern over the Red Sea. By the effect monsoon, system NNW wind blows in the northern part and wind blows NNW in the summer and shifted to SSE during the winter [8]. This seasonal strong wind pattern and associated circulations will influence the tidal dynamics along the coastline of the Red Sea. The SST of Red Sea is very high during the summer and precipitation is very less all over the year. The sea level of the Red sea also changing with respect to wind associated circulation pattern [9] [10] [11] [12] [13].

\section{Data and Methodology}

The present study used time series data from seven stations along the east coast of Red Sea which were obtained from the General Commission for Survey (GCS), Kingdom of Saudi Arabia. The tide gauges distributed along the coastline are shown in Figure 1. The time series data are available from Sept. 2012-Aug. 2013 at 1-hour interval. The data were processed and used for analysis. The one-year data will almost cover all astronomical influences on water level. The study uses T-tide (developed by University of British Colombia, Canada) software for analysis. T-tide works in Matlab platform, can be used to perform classical harmonic analysis with nodal corrections, inference, and a variety of user 


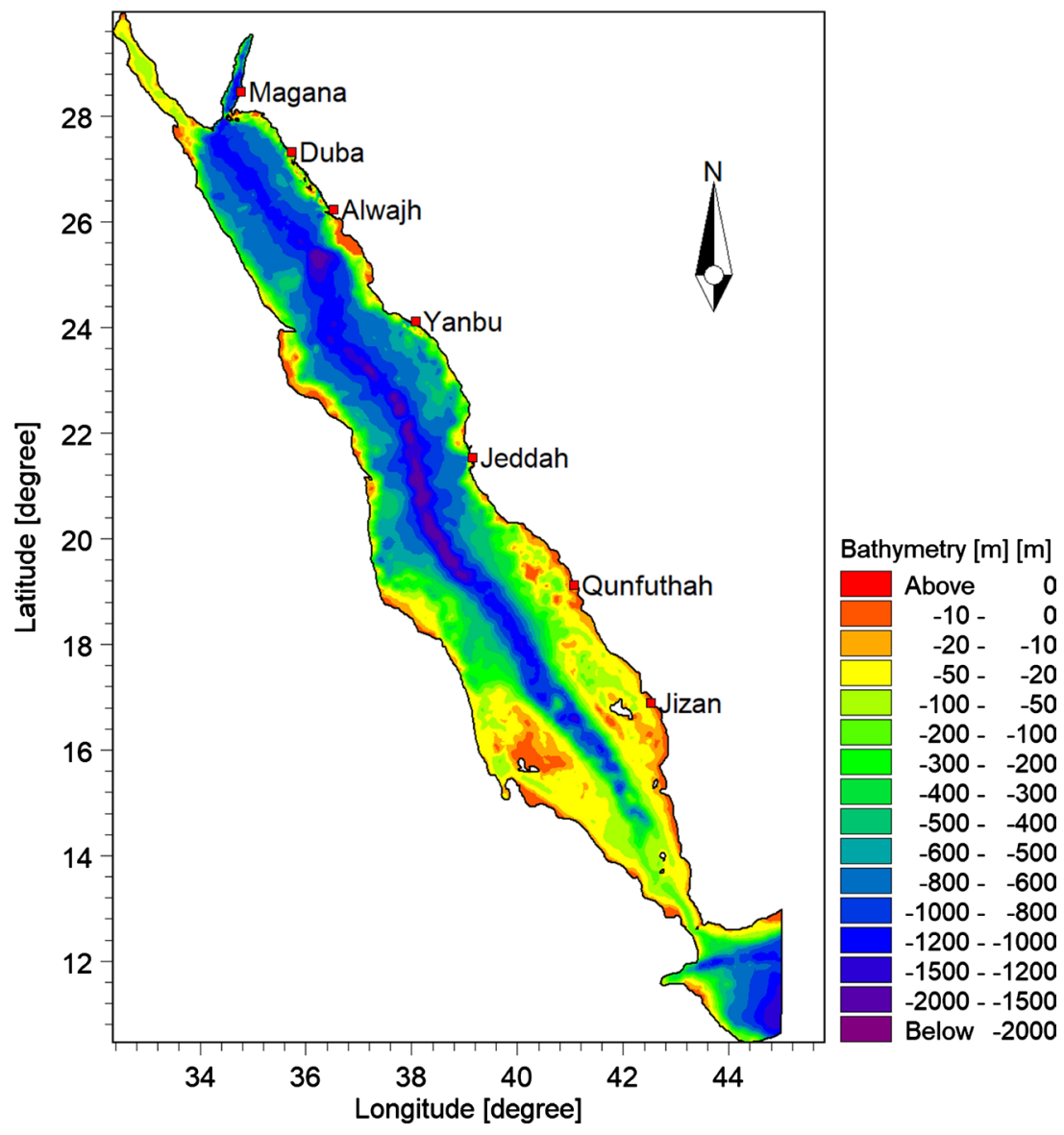

Figure 1. Study area and coastal stations.

specified options [14]. The T-tide derives tidal constituents due to astronomical forces and signal analysis which can carry out. The predication can be carried out using the same tool. The toolbox can be used to plot the analysed time series data with residual tide. The present investigation forces temporal variability of tidal constituents using the toolbox.

\section{Results and Discussion}

The one years of water levels in all the coastal stations processed using T-tide to derive the tidal constituents at seven coastal stations along the east coast of Red Sea. The amplitudes of resolved constituents are listed in Table 1. The important tidal constituents were derived to study their seasonal and temporal variations. Since tidal wave, propagates to shallow water subjected to different physical processes such as amplifications, distortion, etc. [15], coastal tidal dynamics are more complex than the open ocean. Since the geometry of the eastern coast of the Red Sea varies irregularly with complex nearshore topography, it reflects in the tidal amplifications in the nearshore area. The amplitudes of derived important tidal constituents are given in Figure 2. The analysis shows that the nature of the tides is of mixed and semi-diurnal type with less amplitude. Among all resolved constituents, M2 (Principal Lunar Semidiurnal) shows selective ampli- 
fications at all coastal stations. The semi diurnal constituents M2 dominant is with more than double amplifications compared to other constituents. The amplification of M2 towards north and south from the Jeddah indicates the

Table 1. Amplitudes (m) of all derived constituents in the seven coastal locations.

\begin{tabular}{|c|c|c|c|c|c|c|c|}
\hline Constituent & Jizan & Qunfudah & Jeddah & Yanmbu & Alwajh & Duba & Magna \\
\hline Q1 & 0.004 & 0.004 & 0.004 & 0.004 & 0.005 & 0.003 & 0.004 \\
\hline RHO1 & 0.001 & 0.001 & 0.002 & 0 & 0.002 & 0.001 & 0.001 \\
\hline 01 & 0.016 & 0.009 & 0.016 & 0.014 & 0.011 & 0.01 & 0.009 \\
\hline M1 & 0.002 & 0.001 & 0.001 & 0.001 & 0.002 & 0.001 & 0.001 \\
\hline P1 & 0.006 & 0.01 & 0.01 & 0.009 & 0.008 & 0.008 & 0.01 \\
\hline S1 & 0.013 & 0.006 & 0.011 & 0.006 & 0.004 & 0.006 & 0.006 \\
\hline $\mathrm{K} 1$ & 0.021 & 0.023 & 0.032 & 0.028 & 0.03 & 0.027 & 0.023 \\
\hline $\mathrm{J} 1$ & 0.002 & 0.002 & 0.002 & 0.002 & 0.001 & 0.002 & 0.002 \\
\hline 001 & 0.002 & 0.002 & 0.002 & 0.002 & 0.002 & 0.002 & 0.002 \\
\hline MNS2 & 0.001 & 0.002 & 0.001 & 0.001 & 0.001 & 0.002 & 0.002 \\
\hline $2 \mathrm{~N} 2$ & 0.019 & 0.016 & 0.006 & 0.011 & 0.015 & 0.015 & 0.016 \\
\hline MU2 & 0.013 & 0.01 & 0.002 & 0.006 & 0.007 & 0.009 & 0.01 \\
\hline N2 & 0.099 & 0.084 & 0.024 & 0.052 & 0.07 & 0.076 & 0.084 \\
\hline NU2 & 0.022 & 0.018 & 0.005 & 0.011 & 0.013 & 0.016 & 0.018 \\
\hline M2 & 0.317 & 0.274 & 0.071 & 0.163 & 0.23 & 0.248 & 0.274 \\
\hline LAM2 & 0.002 & 0.001 & 0.001 & 0.001 & 0.001 & 0.001 & 0.001 \\
\hline L2 & 0.01 & 0.008 & 0.003 & 0.005 & 0.006 & 0.008 & 0.008 \\
\hline $\mathrm{T} 2$ & 0.005 & 0.006 & 0.002 & 0.004 & 0.006 & 0.005 & 0.006 \\
\hline S2 & 0.102 & 0.083 & 0.017 & 0.044 & 0.071 & 0.071 & 0.083 \\
\hline $\mathrm{R} 2$ & 0.002 & 0.002 & 0.001 & 0 & 0.004 & 0.002 & 0.002 \\
\hline K2 & 0.028 & 0.022 & 0.006 & 0.015 & 0.021 & 0.022 & 0.022 \\
\hline 2SM2 & 0.002 & 0.002 & 0.001 & 0.001 & 0.002 & 0.001 & 0.002 \\
\hline $2 \mathrm{MK} 3$ & 0.002 & 0.002 & 0.001 & 0 & 0.001 & 0.002 & 0.002 \\
\hline M3 & 0.003 & 0.004 & 0.001 & 0.001 & 0.003 & 0.003 & 0.004 \\
\hline MK3 & 0.005 & 0.005 & 0.002 & 0.001 & 0.003 & 0.004 & 0.005 \\
\hline MN4 & 0 & 0.001 & 0 & 0 & 0 & 0 & 0.001 \\
\hline M4 & 0.003 & 0.001 & 0.001 & 0 & 0 & 0 & 0.001 \\
\hline MS4 & 0.003 & 0.001 & 0.001 & 0 & 0.001 & 0.001 & 0.001 \\
\hline S4 & 0.001 & 0.001 & 0.002 & 0.001 & 0.001 & 0.001 & 0.001 \\
\hline 2MN6 & 0.001 & 0 & 0 & 0 & 0 & 0 & 0 \\
\hline M6 & 0.001 & 0 & 0 & 0 & 0 & 0 & 0 \\
\hline $2 \mathrm{MS} 6$ & 0 & 0.001 & 0 & 0 & 0 & 0 & 0.001 \\
\hline S6 & 0 & 0 & 0 & 0.001 & 0 & 0.001 & 0 \\
\hline
\end{tabular}



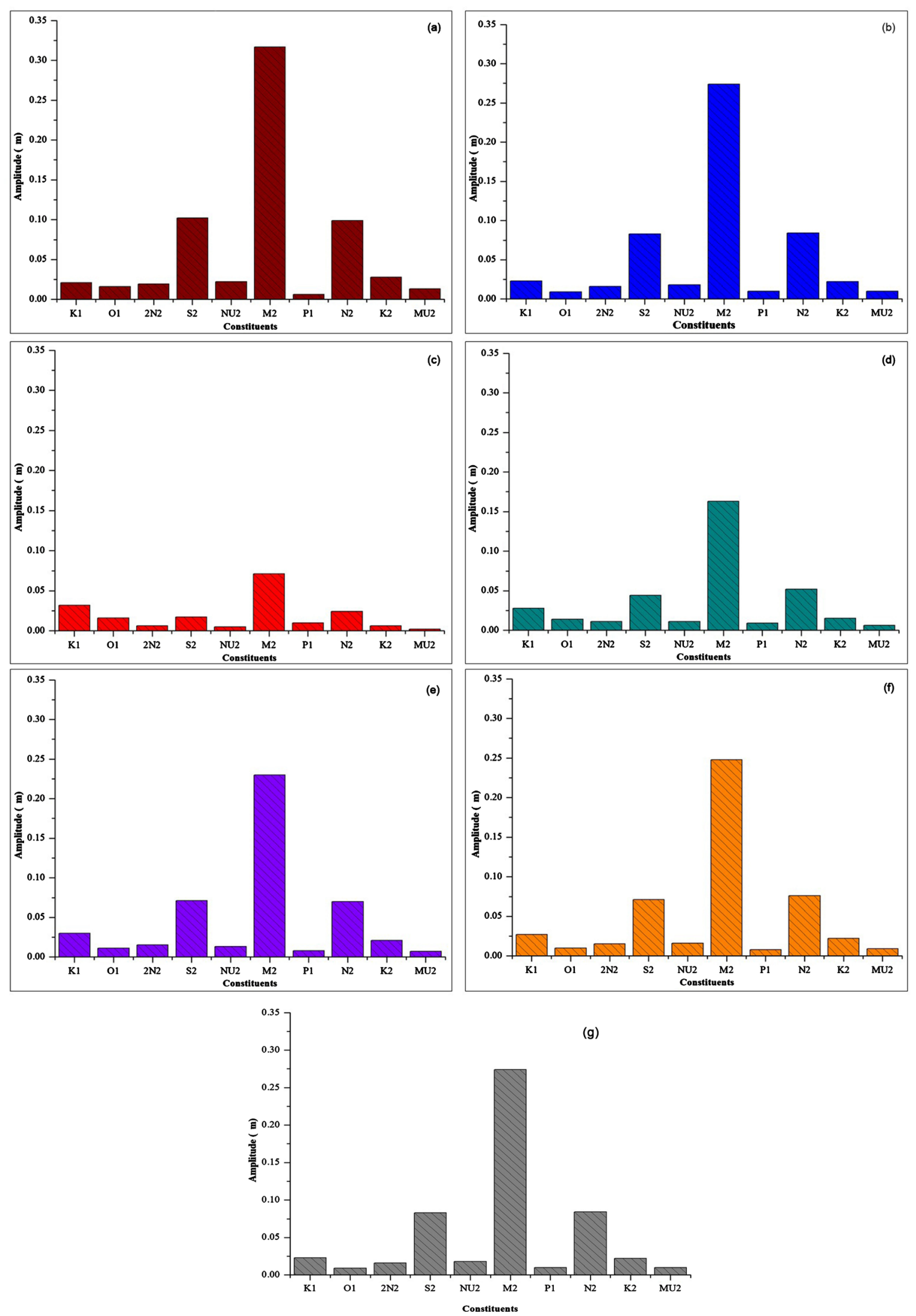

Figure 2. Variation of amplitudes of significant tidal constituents along the seven coastal stations: (a) Jizan (b) Qunfudah (c) Jeddah (d) Yanbu (e) Al wajh (f) Duba (g) Magna. 
presence amphidromic points in the central part of the Red Sea. The less amplification of the constituents M2 is quite evident from the tidal range from field signature $(\sim 20 \mathrm{~cm})$. The other important constituents S2 (Principal Solar semidiurnal) and K1 (Luni-solar diurnal) shows amplification compared to other important constituents. The S2 shows much amplification than K1 among all the stations except Jeddah, which is the central part of the Red Sea, having amphidromic feature. The other constituents (O1, 2N2, NU2, P1, N2, K2, and MU2) have also shows spatial variability in amplitudes along the eastern coast of the Red Sea. Other important features are the diurnal constituents which show increased amplifications from north and south towards the center of the eastern coast of the Red Sea, which is of the reverse pattern of the semi-diurnal constituents, which show in amplification along the coastal line. Among the diurnal and semi diurnal components, semi-diurnal components show much amplification than the diurnal components and well represent astronomical tidal characteristics along the eastern coast of the Red Sea.

The present study also made a detailed analysis of spatial variations of phase of important tidal constituents (O1 (Lunar diurnal constituent), K1, 2N2 (Lunar elliptic semi diurnal second-order constituent), S2, M2, P1 (Solar diurnal constituent), N2 (Larger lunar elliptic semi diurnal constituent), K2 (Lunisolar semi diurnal constituent), NU2 (Larger lunar evectional constituent), MU2 (Vibrational constituent)) to understand the tidal dynamics along the eastern coast of the Red Sea (Figure 3). It can be seen that the main semi-diurnal components have almost same phase along the eastern coast of the Red Sea except Jizan. The water depth and presence islands in the Jizan alter the phase of the tidal wave propagates from the central Red Sea. The K1 shows almost reverse phase than

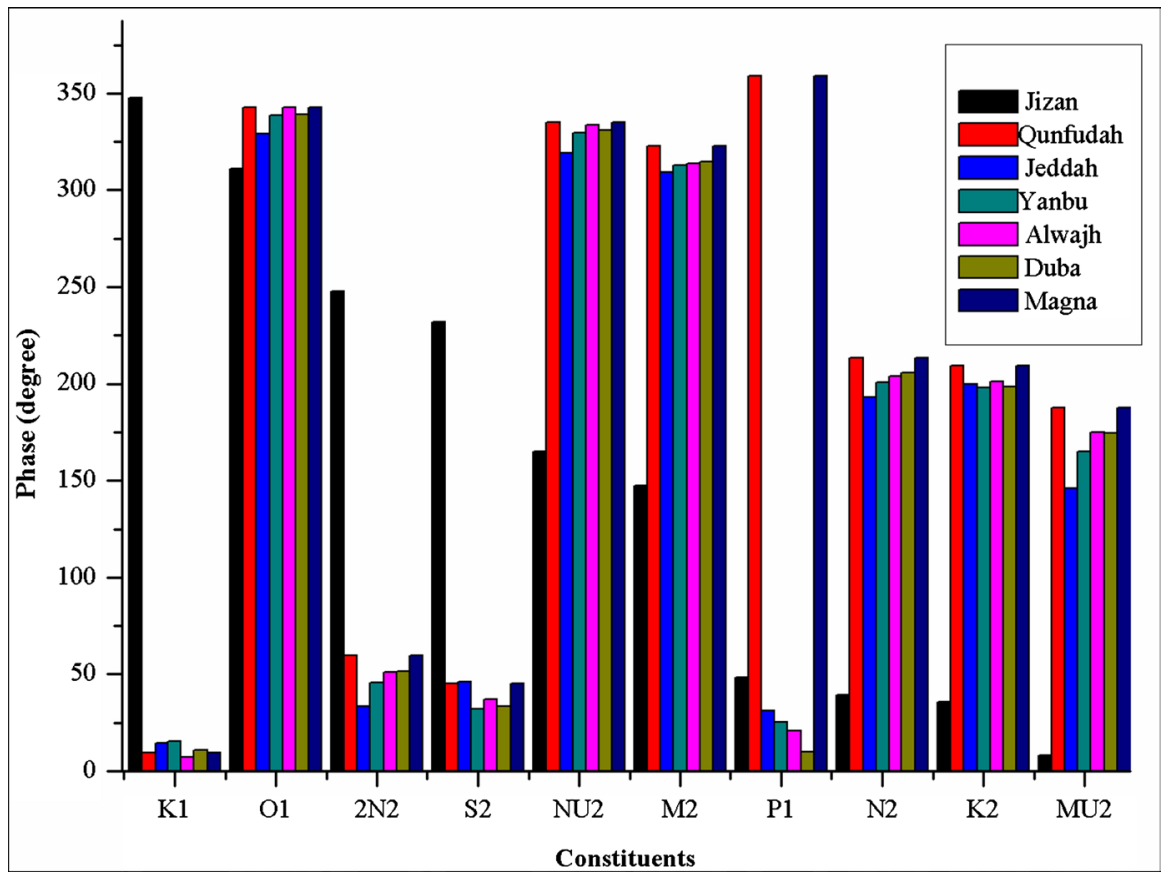

Figure 3. Variation of phase of significant tidal constituents along the seven coastal stations. 
the major constituents M2, where K1 has different phase for Jizan coast. The complex topography in the nearshore area and in the Red Sea will affect the phase distributions of important tidal constituents along the coastal line and is quite evident from Figure 3. Since there is no river discharge in the nearshore area, the possibility of nonlinear interaction between the tides and river runoff is very less and hence the nearshore topography act as main causative factor for nearshore tidal wave dynamics.

\subsection{Water Level Predictions}

The T-tide tool used to predict water level at the Yanbu coastal stations for 30 days during July 2015. There is reasonably good fit between the measurements and predicted in the selected location (Figure 4). The correlation coefficients are reasonably good (0.96) in the location and RMS value is 0.92 . Hence, T-tide predictions are reasonably good and can be used as a prediction tool along the coastline.

\subsection{Form Factor Study}

The derived amplitude used to classify tide regime in the eastern coast of the Red Sea. The importance of diurnal or semi-diurnal tide and its classifications can be expressed in terms of form factor $\mathrm{F}$ [16].

$$
\mathrm{F}=(\mathrm{K} 1+\mathrm{O} 1) /(\mathrm{M} 2+\mathrm{S} 2)
$$

where the symbols of the constituents indicate their respective amplitudes. The form factor calculated from derived constituents presented in Table 2. The values

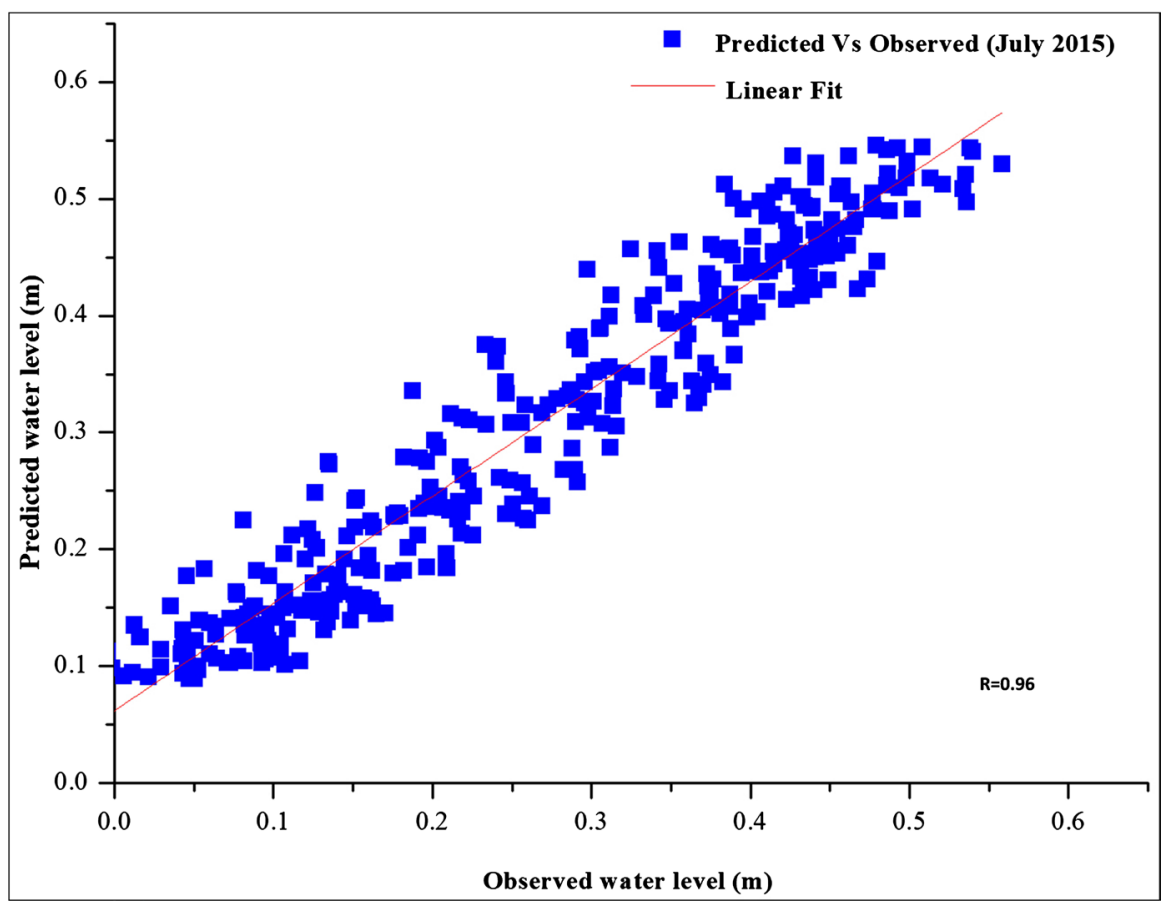

Figure 4. Correlation between observed and predicted water level at Yanbu during July 2015. 
Table 2. Form factors at different coastal locations.

\begin{tabular}{rc}
\hline Coastal Stations & Form factor \\
\hline Magna & 0.0896 \\
Duba & 0.1159 \\
Alwaj & 0.1362 \\
Yanbu & 0.2028 \\
Jeddah & 0.5454 \\
Qunfuthah & 0.0896 \\
Jazan & 0.0883 \\
\hline
\end{tabular}

of form factor show tides in the all the coastal stations are in semi-diurnal nature except Jeddah, where tide mainly mixed semi-diurnal nature. The form factor is higher in the central coast and decreases towards south and north coastal stations. The study also points out the semi diurnal and mixed semi-diurnal characteristics of the tide along the eastern coast of the Red Sea.

\section{Summary and Conclusion}

Study shows tide plays important role in the near shore area of the eastern coast of the Red Sea. The one-year time series data were from the coastal stations along the eastern coast of the Red Sea used for the analysis. The compressive analysis of tidal data using T-Tide in the coastal areas unravels the spatial variations of tidal dynamics due to different environmental factors. The T-tide tool is used to compute the equilibrium tidal amplitude and phase from astronomical forces. From the analysis, semi diurnal constituents M2 dominant is with more than double amplifications compared to other constituents. The M2 plays a major role in the total tidal range in the region than other major constituents. The study phase variations of major constituents also show different tidal dynamics along the eastern coast of the Red Sea. The form factor study was also used to find the nature of tidal pattern along the coastal region.

\section{Acknowledgements}

The author thanks Dean, Faculty of Maritime Studies, King Abdulaziz University for support. I also thanks to Shanas P for his help during the preparation of the manuscript. The authors also thank General Commission for Survey (GCS), Kingdom of Saudi Arabia for providing the data and support.

\section{Conflicts of Interest}

The author declares no conflicts of interest regarding the publication of this paper.

\section{References}

[1] Al-Barakati, M.A. (2009) Water Exchange of Sharm Obhur, Jeddah, Red Sea. Jour- 
nal of King Abdulaziz University-Marine Sciences, 20, 49-58.

[2] Berumen, M.L., Hoey, A.S., Bass, W.H., Bouwmeester, J., Catania, D., Cochran, J.E.M., Khalil, M.T., Miyake, S., Mughal, M.R., Spaet, J.L.Y. and Saenz-Agudelo, P. (2013) The Status of Coral Reef Ecology Research in the Red Sea. Coral Reefs, 32, 737-748. https://doi.org/10.1007/s00338-013-1055-8

[3] Al Barakati, A.M. (2012) The Flushing Time of an Environmentally Sensitive, Yanbu Lagoon along the Eastern Red Sea Coast. International Journal of Science and Technology, 1.

[4] Smeed, D. (2004) Exchange through the Babel Mandeb. Deep-Sea Research, 51, 455-474.

[5] Behairy, A.K.A., Al-Kholy, A.A., Hashem, M.T. and El-Sayed, K.H. (1983) Preliminary Study on the Geology and Fisheries of the Coastal Area between Jeddah and Yanbu. Journal of the Faculty of Marine Science, 2, 1-47.

[6] Bird, E. (2008) Coastal Geomorphology: An Introduction Paperback. Wiley, Hoboken.

[7] Guilcher, A. (1955) Geomorphology of the Northern End of Farsan Bank (Red Sea). Annals of the Oceanographic Institute, 30, 55-100.

[8] Khalid, M. (2010) Sea Level Variations at Jeddah, Eastern Coast of the Red Sea. Journal of King Abdulaziz University-Marine Sciences, 21, 73-86.

https://doi.org/10.4197/mar

[9] Ahmad, F. and Sultan, S.A.R. (1993) Tidal and Sea Level Changes at Jeddah, Red Sea. Pakistan Journal of Marine Sciences, 2, 77-84.

[10] Sultan, S.A.R., Ahmad, F. and Elghribi, N.M. (1995) Sea Level Variability in the Red Sea. Oceanologica Acta, 18, 607-615.

[11] Sultan, S.A.R. and Ahmad, F. (2000) Annual and Semi-Annual Variations of Sea Level at Jeddah, Central Coastal Station of the Red Sea. Indian Journal of Marine Sciences, 29, 201-205.

[12] Maghrabi, S.O. (2003) Variations of Mean Sea Level in the Red Sea. Master Thesis, King Abdulaziz University, 98 p.

[13] Sultan, S.A.R. and Elghribi, N.M. (2003) Sea Level Changes in the Central Part of the Red Sea. Indian Journal of Marine Sciences, 32, 114-122.

[14] Pawlowicz, R., Beardsley, B. and Lentz, S. (2002) Classical Tidal Harmonic Analysis Including Error Estimates in MATLAB Using T_TIDE. Computers and Geosciences, 28, 929-937. https://doi.org/10.1016/S0098-3004(02)00013-4

[15] Rose, L. and Bhaskaran, P.K. (2016) The Role of Environmental Forcing on Tidal Dynamics along Complex Near-Shore Waters off Bangladesh. Ocean Engineering, 116, 68-81.

[16] Boon, J.D. (2004) Secrets of the Tide: Tide and Tidal Current Analysis and Predictions, Storm Surges and Sea Level Trends. Horwood Publishing, Chichester, 212 p. 